ORIGINAL ARTICLE

\title{
Delayed chemoreceptor responses in infants with apnoea
}

\section{Katz-Salamon}

Arch Dis Child 2004;89:261-266. doi: 10.1136/adc.2003.030957

\begin{abstract}
Aims: To test the hypothesis that apnoea of infancy (AOI) is due to a deficit in chemoreception. Methods: Tests were performed on 112 infants: 43 healthy control infants, 28 infants with periodic breathing or central apnoea (PBCA), and 41 infants with obstructive apnoea (OA) on overnight polysomnography. Chemoreceptor responses to hypercapnia (4\% and $6 \% \mathrm{CO}_{2}$ in air) for $6-8$ minutes and hyperoxia $\left(100 \% \mathrm{O}_{2}\right)$ for 60 seconds were expressed in terms of response strength and reaction time. Age at birth (gestational week 37-41) and age at test (2-34 postnatal weeks) were comparable across groups (median, min-max value). A total of $70 \mathrm{CO}_{2}$ and $71 \mathrm{O}_{2}$ tests were analysed.

Results: The strongest and fastest $\mathrm{CO}_{2}$ responders were control infants: their median increase in ventilation was $291 \% / \mathrm{kPaCO}_{2}$ and their reaction time 16 breaths. In infants with PBCA and OA, the increase in ventilation was $41 \%$ and $130 \% / \mathrm{kPaCO}_{2}$, and reaction time 64 and 54 breaths, respectively. There was a significant negative correlation between $\mathrm{CO}_{2}$ response strength and response time. In response to hyperoxia there was a comparable decrease in ventilation in all infants (12-20\%), but a significantly longer response time in infants with apnoea (20 v 12 breaths). There was no correlation between the response strength and response time to $\mathrm{O}_{2}$ and $\mathrm{CO}_{2}$.

Conclusion: An inappropriate central control of respiration is an important mechanism in the pathogenesis of apnoea of infancy.
\end{abstract}

Correspondence to: Assoc. Prof. M KatzSalamon, Dept for Women's and Child Health, Karolinska Institute, Elevhemmet H1O2, S-171 76

Stockholm, Sweden; miriam.katz-salamon@ ks.se

Accepted 2 July 2003
$\mathrm{T}$ he breathing pattern of healthy very preterm and term infants during the first six months of life is irregular and periodic, and includes episodes of apnoea of variable duration. Apnoeas are also observed in adults, but are associated predominantly with diseases.

The causes of apnoea in infants and adults are complex, and vary between individuals. The aetiology includes anatomical factors, neuromuscular weakness, and central nervous system disturbances. Many studies have also associated apnoea with chemoreceptor dysfunction. The rationale for this association is reasonable, given that drive from the peripheral and central chemoreceptors to the respiratory centres in the brain stem is essential for the generation and maintenance of a normal breathing rhythm during sleep. The strength of the chemoreceptor response to changes in the levels of $\mathrm{CO}_{2}$ and $\mathrm{O}_{2}$ in the blood and brain tissue is easily quantified by measuring the resulting change in ventilation, and can be used as an index of the function of central structures controlling respiration.

A review of studies on association between apnoeas and chemoreception reveals discordant results: some adults with obstructive sleep apnoeas (OSA) have blunted ventilatory response to chemical stimulation, ${ }^{1-3}$ while others have an increased responsiveness to hypercapnia. ${ }^{4-6}$ Very preterm infants with apnoea and periodic breathing exhibit diminished chemoreceptor responsiveness, ${ }^{7-9}$ while full term infants with OSA can exhibit either subtle changes, ${ }^{10}{ }^{11}$ or normal responses to hypercapnia. ${ }^{12}$

It can be difficult to make a clear and unequivocal distinction between different types of apnoeas. There is considerable evidence, for example, that central and obstructive/mixed apnoeas both share some element of upper airway instability. ${ }^{13-15}$ It is also evident that central drive mechanisms control both upper airway and chest wall muscles in order to maintain stability in breathing. ${ }^{16}{ }^{17}$

In general, the sensory systems react to changes in the external and/or internal environment promptly, and with finely tuned responses. Thus, an appropriate response must occur with sufficient strength, and within an optimal time interval. A response which is too weak, too strong, and/or delayed might destabilise the system, resulting in inadequate compensation.

The present study addressed the hypothesis that chemoreceptor dysfunction, described both in terms of response strength as well as reaction time, ${ }^{18}{ }^{19}$ could be an important contributing factor to the aetiology of apnoea of infancy. If infants with obstructive and central apnoeas have weak or delayed chemoreceptor responses, this would be evidence for a dominant role played by central respiratory control mechanisms in the pathogenesis of apnoea. However, if chemoreceptor responses of these infants are intact, this would indicate that factors other than the central respiratory drives are important in triggering apnoea. The approach of describing chemoreception in terms of strength and response time, has been validated in three recent studies from this ${ }^{18} 19$ and other laboratories. ${ }^{20}$

\section{METHODS \\ Subjects}

The study population consisted of 112 infants, 69 infants with apnoea of infancy (AOI) and 43 healthy controls. Infants with AOI were recruited from infants routinely referred to the Karolinska Hospital for evaluation of sleep disordered breathing, and were included only after other possible causes of apnoea (for example, infection, congenital heart disease, or seizures) had been excluded by the referring hospital/physician. Infants with craniofacial anomalies and other, severe medical conditions were also excluded from the study. On the basis of the polysomnographic recordings, the AOI group was subdivided into two subgroups: (1) infants with periodic breathing and central apnoeas ( $\mathrm{PBCA}, \mathrm{n}=28$ ); and (2) infants with obstructive apnoeas (OA, $\mathrm{n}=41$ ). Within these two groups, the duration and frequency of apnoea (apnoea index $=$ number of apnoeas/1 hour recording time) were calculated.

Abbreviations: $A L T E$, apparent life threatening event; $A O I$, apnoea of infancy; CA, central apnoea; OSA, obstructive sleep apnoea; $\mathrm{PB}$, periodic breathing; $P B C A$, periodic breathing and central apnoea 
Table 1 Population characteristics

\begin{tabular}{|c|c|c|c|c|c|c|c|}
\hline & $\begin{array}{l}\text { Age at birth } \\
\text { (wk) }\end{array}$ & $\begin{array}{l}\text { Birth } \\
\text { weight }(\mathrm{kg})\end{array}$ & $\begin{array}{l}\text { Age at test } \\
\text { (wk) }\end{array}$ & $\begin{array}{l}\text { Respiratory rate at rest } \\
\text { (breaths/min) }\end{array}$ & $\begin{array}{l}\text { Apnoea index } \\
\text { (no./hour) }\end{array}$ & Bradycardias* & Desaturations* \\
\hline Healthy controls ( $n=43$ ) & $\begin{array}{l}40 \\
(37-41)\end{array}$ & $\begin{array}{l}3.5 \\
(2.9-4.2)\end{array}$ & $\begin{array}{l}12 \\
(4-40)\end{array}$ & $\begin{array}{l}26.7 \\
(17-53)\end{array}$ & 0 & 0 & 0 \\
\hline \multicolumn{8}{|l|}{ Apnoea of infancy $(n=69)$} \\
\hline $\mathrm{PBCA}(n=28)$ & $\begin{array}{l}38.2 \\
(37-41)\end{array}$ & $\begin{array}{l}3.2 \\
(2.8-4.0)\end{array}$ & $\begin{array}{l}10 \\
(2-44)\end{array}$ & $\begin{array}{l}32.4 \\
(21-49)\end{array}$ & $\begin{array}{l}3 \\
(1-7.2)\end{array}$ & $\begin{array}{l}2 \\
(0-4)\end{array}$ & $\begin{array}{l}14 \\
(3-25)\end{array}$ \\
\hline $\operatorname{OSA}(n=41)$ & $\begin{array}{l}39.9 \\
(37-41) \\
p=0.24\end{array}$ & $\begin{array}{l}3.4 \\
(2.9-4.1) \\
p=0.09\end{array}$ & $\begin{array}{l}12 \\
(4-36) \\
p=0.54\end{array}$ & $\begin{array}{l}27.8 \\
(21-50) \\
p=0.04 \\
P B C A \neq \text { controls }=O A\end{array}$ & $\begin{array}{l}2.9 \\
(1-9)\end{array}$ & $\begin{array}{l}11 \\
(0-14)\end{array}$ & $\begin{array}{l}32 \\
(4-41)\end{array}$ \\
\hline
\end{tabular}

The numbers represent medians (min-max).

*Bradycardias, fall in HR by $<20 \%$; desaturations, $\mathrm{SaO}_{2}<90 \%$.

The control group consisted of healthy infants (see table 1) who were born vaginally, at term, after an uneventful pregnancy at the Karolinska Hospital. Thirteen of the control infants were also part of a control cohort who participated in a collaborative Nordic study on infants with apparent life threatening events (ALTE). These 13 control infants matched AOI infants in terms of gestational age at birth; ${ }^{21}$ the remaining 30 control infants were healthy infants who showed no cardiorespiratory abnormalities on polysomnography.

None of the infants were receiving medication at the time of the study, and none of the mothers smoked during pregnancy or after delivery.

Periodic breathing and central apnoeas during sleep An episode of periodic breathing (PB) was defined as three or more respiratory pauses lasting at least three breaths within 20 seconds or less. ${ }^{22}$ A cycle of PB was defined as the interval from the beginning of one respiratory pause to the beginning of the next pause. Central apnoea (CA) was defined as respiratory arrest preceded by synchronous movements of the chest and abdomen.

\section{Obstructive apnoeas}

Obstructive apnoea (OA) was defined as two or more breaths associated with paradoxical inverse movements of chest and abdomen and a decrease in $\mathrm{SaO}_{2}$ of at least 3\%.

\section{Sleep state definition}

Sleep states were categorised by a single trained observer according to standard behavioural criteria, ${ }^{23}$ and analysed in conjunction with respiratory patterns and variations in heart rate (HR). Only tests performed during quiet sleep were analysed (defined by eyes closed, absence of rapid eyes movements, regular respiratory and HR patterns, and absence of gross body movements except for occasional startles.)

\section{Polysomnographic recording}

Infants were admitted to the laboratory at approximately $8 \mathrm{pm}$, and settled to sleep supine and lightly dressed. No sedation or sleep deprivation was used. The room temperature was maintained at $20-21^{\circ} \mathrm{C}$, and the lights were dimmed. All infants were monitored for 6-8 hours overnight, using one of two computerised polysomnography systems (CARDAS, Maternal and Infant Telemonitoring Centre, Oxford, UK and Rembrandt, MedCare Automation). The amplitude and frequency of respiratory movements of the chest and abdomen were recorded using inductance plethysmography (Respitrace). The sum of the amplitude of chest and abdominal movements was proportional to "tidal volume". A three lead ECG measured the beat-to-beat R-R interval, and a finger pulse oxymeter probe recorded $\mathrm{SaO}_{2}$ and pulse amplitude. Skin $\mathrm{PO}_{2}\left(\mathrm{TcPO}_{2}\right)$ and $\mathrm{PCO}_{2}\left(\mathrm{TcPO}_{2}\right)$ tensions were monitored with a combined transcutaneous electrode (Radiometer TCM3 Copenhagen, Denmark). A wrist movement sensor registered body position and movements. Nasal airflow was recorded in 51 of 71 infants. Airflow could not be recorded in 13 control infants monitored by the CARDAS system (this system did not include airflow measurements in the montage), and in seven infants with AOI who did not tolerate nasal prongs.

Analogue signals generated by thoracic and abdominal movements, oxygen saturation, airflow, $\mathrm{TcPO}_{2}, \mathrm{TcPCO}_{2}$, and RR intervals were digitally sampled at 10,20 , and $100 \mathrm{~Hz}$ respectively.

Both polysomnographic systems permitted real time replay of the digitised data, and its export into commercial statistical software (Statgraphics).

\section{Hypercapnic test}

During the first quiet sleep period, a $\mathrm{CO}_{2}$ challenge was performed. A polycarbonate, 10 litre head box was gently placed over the infant's head. Following a 3 minute control period breathing room air (flowing through the box at $10 \mathrm{l} / \mathrm{min}$ ), the gas flow was switched to $4 \%$, and then to $6 \%$ $\mathrm{CO}_{2} \cdot \mathrm{CO}_{2}$ inhalation was continued for 6-8 minutes, or until the infant moved or changed body position. In three infants the hypercapnic test was abandoned, due either to arousal (two infants) or a startle (one infant). These three infants were retested once quiet sleep had resumed, because calculation of "tidal volume" from respiratory excursions is unreliable following movement. The minimum duration of tests accepted for analysis was 6 minutes.

Only one successful test on each infant was performed.

\section{Hyperoxic test}

Hyperoxic tests were performed during the second epoch of quiet sleep in all except the three infants who aroused/ startled during the initial carbon dioxide test. In these three infants the hyperoxic test was administered during the third epoch of quiet sleep. Following a 1-2 minute control period in room air, the gas flow through the hood was rapidly switched to $100 \%$ humidified oxygen for 60 seconds, followed by a return to air at the same flow rate.

Only one successful test on each infant was performed.

Following hypercapnic and hyperoxic testing, polysomnographic recording continued overnight, in order to evaluate number of apnoeas (apnoea index), bradycardias (HR decrease by $>20 \%)$, and desaturations $\left(\mathrm{SaO}_{2}<90 \%\right)$ throughout the night.

All procedures were approved by the Ethics Committee at the Karolinska Hospital.

\section{Data analysis}

Because the induction plethysmography signal was not directly calibrated for volume, values of tidal volume and minute ventilation are given in quotation marks. 
Mean values of the sum of the amplitude of chest/ abdominal respiratory movements ("tidal volume"), respiratory rate (RR), $\mathrm{TcPCO}_{2}, \mathrm{TcPO}_{2}$, and $\mathrm{SaO}_{2}$, during the one minute baseline period (air breathing) preceding the onset of $\mathrm{CO}_{2}$ and $\mathrm{O}_{2}$ challenges were used as resting, reference values.

Breath-by-breath values of "ventilation" during hypercapnic and hyperoxic tests were calculated from the respiratory rate multiplied by the "tidal volume". All recordings were scanned thoroughly to exclude artefacts and sighs, ensuring that the quality of the signals was acceptable for statistical analysis. Only recordings which satisfied these requirements were analysed. As a consequence of this selection process, 42 hypercapnic and 41 hyperoxic tests were discarded from the final analysis (fig 1).

\section{"Ventilatory" response to hypercapnia}

A representative tracing is provided in fig 2A. Changes in "ventilation" during the entire 6-8 minutes were used to calculate the ventilatory response to hypercapnia. Breath-bybreath "ventilation" was expressed as percentage change from the reference period (assigned 100\%) - that is, a $50 \%$ increase in "ventilation" was expressed as $150 \%$ change in "ventilation", while a 50\% decrease was denoted as $50 \%$.

\section{Response strength}

Change in "ventilation" (y axis) was plotted against the corresponding change in $\mathrm{TcPCO}_{2}$ (x axis). Regression analysis was then used to calculate the slope. The slope of the regression line thus described the percentage change in "ventilation" per unit change in $\mathrm{TcPCO}_{2}\left(\Delta\right.$ vent $\left./ \Delta \mathrm{TcPCO}_{2}\right)$, giving an index of the strength of the ventilatory response to $\mathrm{CO}_{2}$. A $\mathrm{p} \leqslant 0.05$ denoted significant correlation between changes in "ventilation" and $\mathrm{TcCO}_{2}$.

"Ventilatory" response to hyperoxia

A representative tracing is provided in fig $2 \mathrm{~B}$.

\section{Response strength}

"Tidal volume" and respiratory rate were analysed on a breath-by-breath basis for each individual. Breath-by-breath "ventilation" was calculated during the 60 seconds air

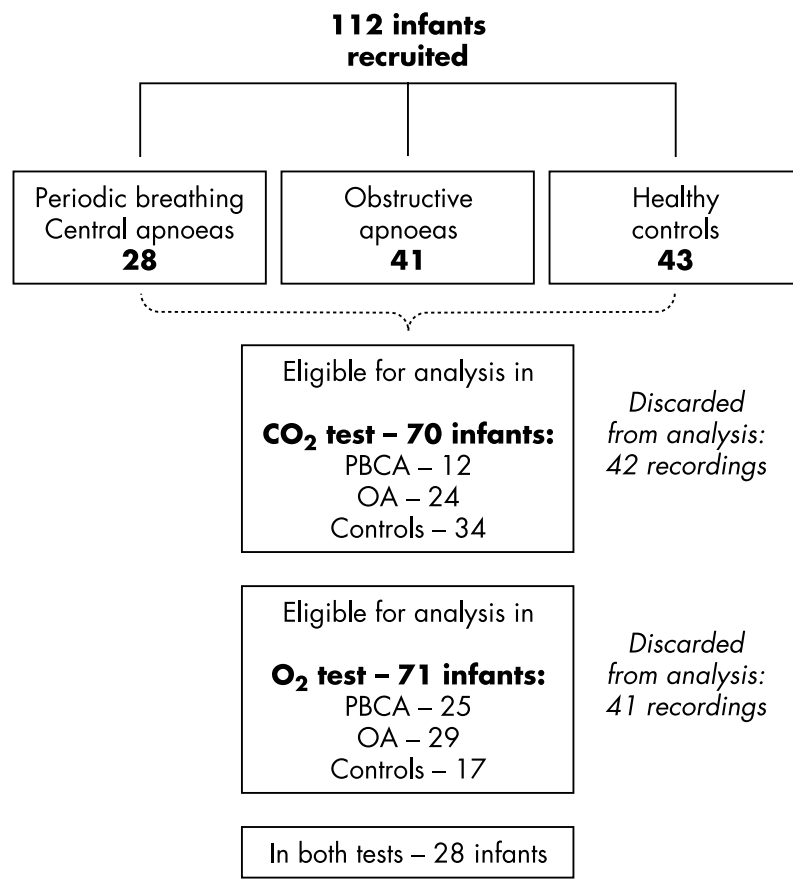

Figure 1 Description of the infant study population. breathing preceding the hyperoxic test (the reference period), and during 60 seconds of oxygen administration. The total number of breaths during the test was split into intervals of four consecutive breaths. The median value of the intervals was calculated. The lowest median that significantly differed from the reference "ventilation" defined the response strength. Non-significant responses were assigned as 0 response.

Response time to hypercapnia/hyperoxia

The response time to inhalation of $4-6 \% \mathrm{CO}_{2}$ or $100 \% \mathrm{O}_{2}$ was estimated as follows: breath-by-breath data were divided into groups of four consecutive breaths, and the median value of these four breaths was calculated. The response time was equivalent to the number of breaths that elapsed between the initiation of hypercapnic/hyperoxic breathing and the first median value of four breaths that significantly differed from the reference median.

Apnoea index

The apnoea index-that is, the number of apnoeas per hour recording time, the median apnoea duration and range, and the number of desaturations and bradycardias were calculated for each individual infant.

Statistical analysis

None of the parameters conformed to a normal distribution as tested by the $\chi^{2}$ goodness-of-fit, Shapiro-Wilks, skewness, and standardised kurtosis tests. Thus, the analyses of all data were based on non-parametric tests. The differences between groups were tested by Kruskall-Wallis analysis of variance of differences between the medians, while correlations between parameters were analysed by Spearman rank correlation.

The relations between the strength of the response, the response time, and the apnoea index, apnoea duration, and number of desaturations and bradycardias, were tested using the rank correlation coefficient.

A $p \leqslant 0.05$ indicated statistically significant differences/ correlations at the $95 \%$ confidence level.

\section{RESULTS}

\section{General findings}

The age at birth and the birth weight, the age at study, resting $\mathrm{TCPCO}_{2}$, and the increase in $\mathrm{TcPCO}_{2}$ in response to $\mathrm{CO}_{2}$ inhalation were comparable in all three groups of infants (table 1). Infants with PBCA had a significantly higher resting respiratory rate than the control group and the group with OA. In infants with apnoea no correlation was found between the number and the duration of apnoeas, on the one hand, and the age at study, on the other $(p=0.58)$.

Significantly more desaturations and bradycardias occurred in infants with OA compared with those with PBCA $\left(\chi^{2}\right.$ without Yates's correction $p=0.04$ and 0.02 respectively, table 1$)$.

\section{Hypercapnic response}

The analysis was based on a total of 70 recordings. The resting $\mathrm{TcCO}_{2}$, as well as the rise in $\mathrm{TcCO}_{2}$ in response to carbon dioxide inhalation were comparable across all three groups (resting $\mathrm{TcCO}_{2}$ varied between 5.50 and $5.45 \mathrm{kPa}$, whilst the $\mathrm{TcCO}_{2}$ increased by $0.4-0.5 \mathrm{kPa}$ ). All infants responded to $4-6 \% \mathrm{CO}_{2}$ with a significant increase in ventilation. The strength of the response was significantly greater in the control group compared with infants with PBCA and OA ( $p=0.002)$ (fig 3$)$. Similarly, the response time was shortest in the control group $(p=0.002)$, while there was no difference between infants with PBCA and OA (fig 4). Because infants with PBCA and OA had comparable responses, they were also analysed together as a single group. Differences between controls and infants with apnoea (that is, PBCA + OA) were more pronounced in terms of 
A



B

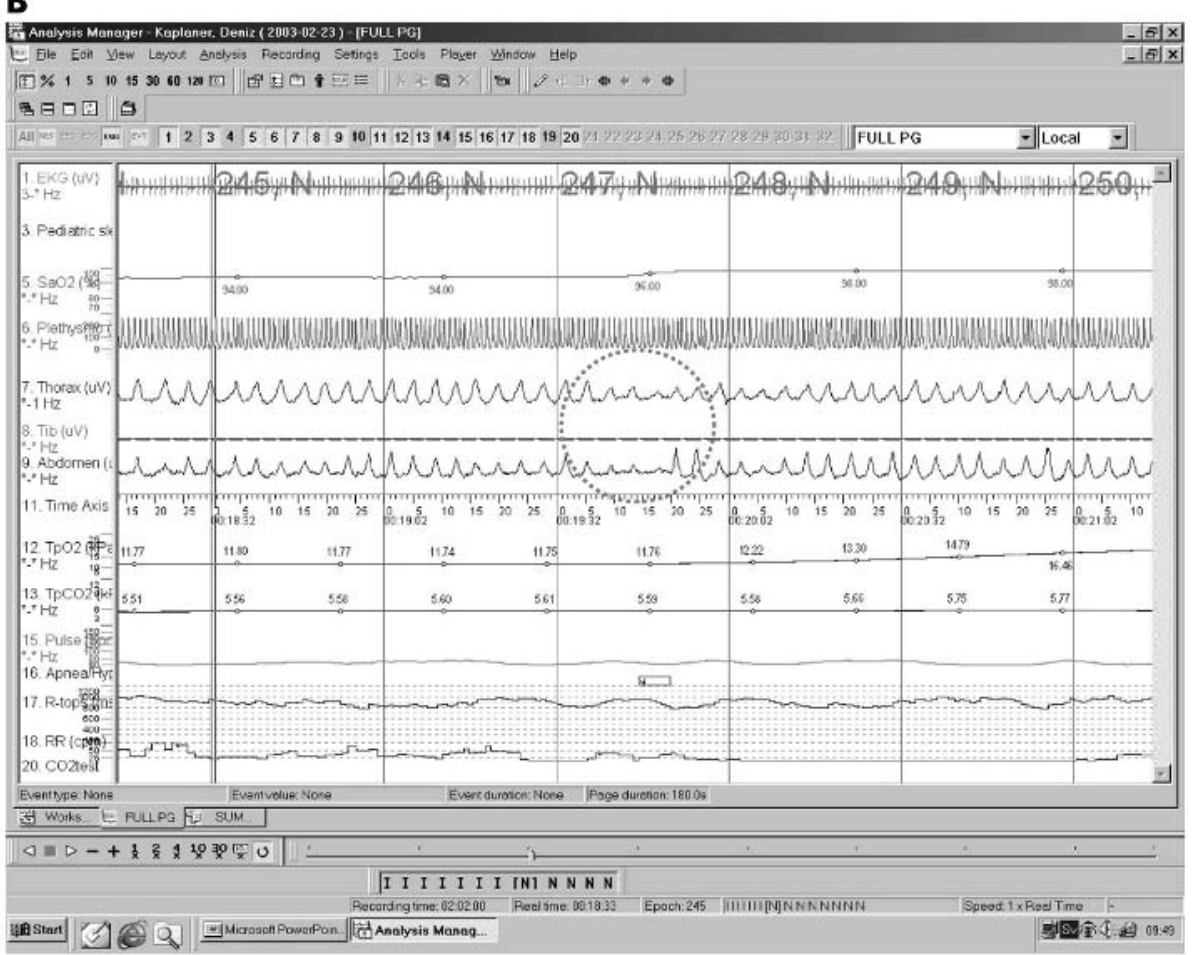

Figure 2 (A) Polysomnographic recording of $\mathrm{CO}_{2}$ challenge test in one infant: note the progressive increase in chest and abdominal excursion and air flow. (B) Polysomnographic recording of $\mathrm{O}_{2}$ challenge test in one infant. Note the decrease in amplitude of chest and abdominal excursions preceding the increase in transcutaneous $\mathrm{PO}_{2}$.

response strength (median slope $291.8 \% / \mathrm{kPa} v 108.0 \% / \mathrm{kPa}$, $\mathrm{p}=0.001)$ as well as response time (16 $v 58$ breaths, $\mathrm{p}=0.0003)$. There was no significant association between response strength, or response time, and the duration and number of apnoeas $(\mathrm{p}=0.08$ and $\mathrm{p}=0.21$ respectively). A significant negative correlation between response strength and response time was found (correlation coefficient $r=-0.71, \mathrm{p}<0.0001)$, indicating that infants with the strongest response were rapid responders, and vice versa.

In 20 infants, the response was due solely to an increase in respiratory rate, while nine infants responded with a significant increase in "tidal volume". The remaining 41 infants responded with a significant increase in frequency and amplitude. 


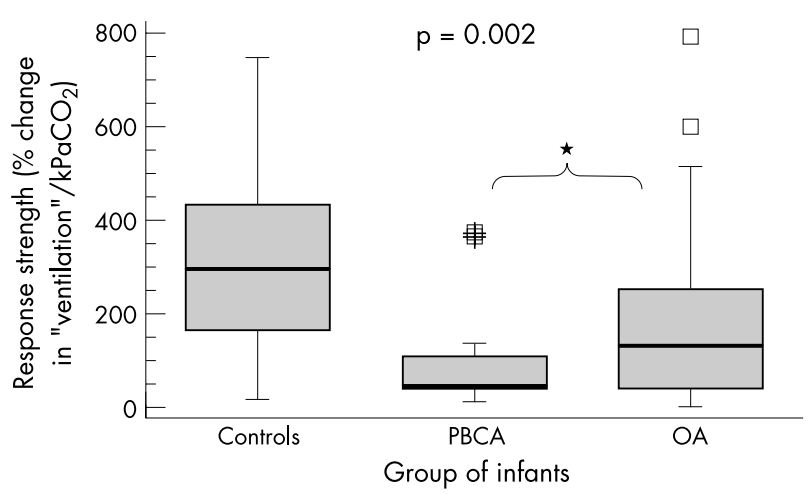

Figure 3 The response strength to $\mathrm{CO}_{2}$ in healthy controls, in infants with periodic breathing/central apnoeas (PBCA) and obstructive apnoeas (OA). The medians are indicated by bold horizontal lines. The rectangles contain $50 \%$ of the values - that is, all values between the lower and upper quartiles. The bars extend out to the minimal and maximum values, while the values below or above 1.5 times the interquartile (outliers) are indicated as small squares (box and whisker plot).

\section{Hyperoxic response}

Hyperoxic tests of 71 infants were analysed (fig 1). There was no significant decrease in ventilation (that is, " 0 " response to $100 \% \mathrm{O}_{2}$ ) in 25 infants: eight controls, six infants with PBCA, and 11 infants with OA. Of the 46 infants with a significant response to $\mathrm{O}_{2}$, there was a significant decrease in "tidal volume" in 13 infants, a decrease in respiratory rate in nine infants, and a decrease in "tidal volume" and respiratory rate in the remaining 25 infants.

The strength of the response was comparable in all three groups: control infants decreased "ventilation" by $28.1 \%$, infants with PBCA by $20.5 \%$, and infants with OA by $21.7 \%$ $(p=0.72)$. There were no differences between the response times of the three groups $(p=0.12)$ : the response time in controls was 12 breaths (4-24), in PBCA infants 20 (8-36) breaths, and OA infants $20(8-80)$ breaths. However, when PBCA and OA infants were combined, infants with apnoea had, overall, a significantly longer reaction time to $\mathrm{O}_{2}$ $(\mathrm{p}=0.04)$ compared with controls: $20(8-80) v 12(4-24)$ breaths, respectively.

\section{The response strength/response time in relation to the apnoea index \\ Carbon dioxide response}

No correlation was found between the response strength/ response time and apnoea index $(\mathrm{p}=0.6$ and 0.25 respectively), or apnoea duration ( $p=0.17$ and 0.09 respectively), or the total number of bradycardias $(\mathrm{p}=0.90$ and 0.35$)$.

\section{Hyperoxic response}

With regard to the carbon dioxide response, there was no correlation between response strength/response time and the number of apnoeas $(\mathrm{p}=0.27$ and 0.65 respectively), or apnoea duration $(p=0.42$ and 0.81 respectively), or the number of bradycardias $(\mathrm{p}=0.27$ and 0.19$)$.

Only 28 eligible recordings of both hypercapnic and hyperoxic tests in the same infant were accepted for analysis (see figl). In this group of infants no associations between the response strength to $\mathrm{CO}_{2}$ and $\mathrm{O}_{2}(\mathrm{p}=0.71)$ as well as the reaction time to the stimuli were found $(p=0.51)$.

\section{DISCUSSION}

The present study has shown that infants with apnoea, regardless of its type and severity, have depressed and delayed ventilatory responses to hypercapnia, and appropriate but somewhat delayed responses to hyperoxia.

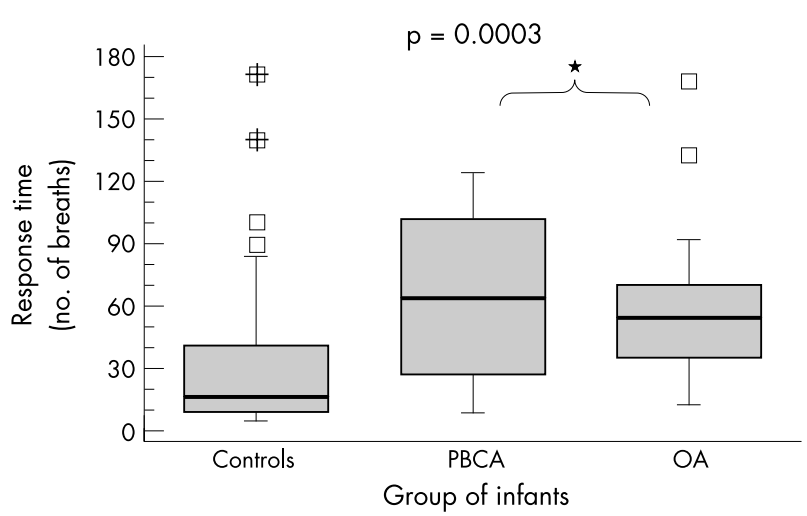

Figure 4 The response time to $\mathrm{CO}_{2}$ inhalation, expressed in number of breaths in healthy controls, in infants with periodic breathing/central and obstructive apnoeas. The medians are indicated by bold horizontal lines. The rectangles contain $50 \%$ of the values - that is, all values between the lower and upper quartiles. The bars extend out to the minimal and maximum values, while the values below or above 1.5 times the interquartile (outliers) are indicated as small squares (box and whisker plot).

To meet homoeostatic demands, the respiratory control mechanisms in the brain stem must rapidly detect and respond to changes in arterial carbon dioxide and oxygen levels. The ventilatory response must be finely tuned in terms of strength as well as timing. A response that is either too weak or too strong could contribute to respiratory control instability resulting, for example, in upper airway obstruction. $^{4-6}$ A response that is too fast or too slow could also destabilise respiration. An inability to promptly correct blood gas-that is, a delay in response time in certain infants, could contribute to the onset of bouts of periodic breathing. Delayed chemoreflex responses could also result in a characteristic waxing and waning of tidal volume and marked oscillations in alveolar $\mathrm{PCO}_{2}$, which falls as breathing increases and rises during the apnoeic spells. ${ }^{24}$ In infants with apnoea, there is a divergence between peripheral and central chemoreflex function. Rigatto and Brady ${ }^{7}$ showed that these infants had normal peripheral but abnormal central chemosensitivity, as did infants with apnoea in the present study.

The diminished central $\mathrm{CO}_{2}$ chemosensitivity and delayed response time of infants with apnoea, together with the fact that their blood gas $\mathrm{CO}_{2}$ and $\mathrm{O}_{2}$ levels at rest are normal, suggests that the principal deficit in these infants is central in origin, and not probably at the peripheral chemoreceptors. This is consistent with the notion that periodic breathing is due to immaturity in central respiratory control in preterm infants, and decreases with age. ${ }^{85}$ The dominant role played by central control mechanisms in the genesis of apnoea is illustrated by the fact that neither obstructive nor central apnoeas occurred during $\mathrm{CO}_{2}$ challenges. The most likely explanation for this is that activation of central chemoreceptors decreases spontaneous fluctuations in respiratory centre output and simultaneously augments the activity of the upper airway muscles. ${ }^{26}$

Although AOI seems to be principally central in origin, respiratory instability could also be enhanced by peripheral factors, for example, a narrow, hypotonic upper airway, compliant chest wall, weak intercostal muscle activity, and strong afferent input from lung stretch receptors. In the months after birth, infants are preferential nose-breathers, and even a small increase in nasopharyngeal resistance could precipitate obstructive apnoea. The importance of the coupling between upper airway muscles and central drive is 
illustrated by the fact that the genioglossus, a pharyngeal dilator, is innervated by a cranial nerve (the hypoglossal), which is functionally connected to the central respiratory control structures. ${ }^{27}$ In infants, lung receptors might contribute to apnoea via the Hering-Breuer inflation reflex. Activation of this reflex terminates inspiration, bringing inspiration to an end; in this way it affects the respiratory frequency. ${ }^{28-30}$ During apnoea, lung volume falls and the afferent input from stretch receptors diminishes, further destabilising the breathing pattern. An applied positive airway pressure largely eliminates apnoeas, possibly by stabilising lung volume and by increasing afferent feedback.

It is doubtful whether findings in infants can be extrapolated directly to explain the pathogenesis of apnoea in adults. Because of maturational changes in respiratory control, the prevalence as well as character of periodic breathing undergoes pronounced, age related changes. ${ }^{24}$ While periodic breathing and apnoea occur frequently in relatively healthy infants, these breathing patterns in adults occur predominantly in association with brain lesions, congestive heart failure (Cheyne-Stokes respiration), obesity, or at high altitude.

\section{Methodological reflections}

Firstly, although measuring ventilatory responses to $\mathrm{CO}_{2} / \mathrm{O}_{2}$ by inductance plethysmography has limitations, its noninvasive nature makes it particularly suitable for clinical studies of young infants. This method is widely used as an index of ventilation, and has previously been validated in infants, ${ }^{31}{ }^{32}$ even though only relative changes in ventilation can be evaluated, and only in the absence of movement artefact. In order to reduce the risk of underestimating ventilation, only tests undisturbed by movement were analysed in the present study.

Secondly, changes in $\mathrm{PCO}_{2}$ were estimated using a transcutaneous electrode rather than by sampling end-tidal gas. The advantage of this is that it avoids irritating of the infant's nasal orifice by a cannula. The disadvantage is that transcutaneous electrodes respond more slowly, although the skin surface $\mathrm{PCO}_{2}$ adequately mirrors the $\mathrm{CO}_{2}$ elimination from the body. Finally, only one hypercapnic and one hyperoxic test were performed in each infant. This was necessary because a long period of undisturbed recording was required to properly evaluate the incidence of apnoeas and bradycardias overnight. Thus, intra-subject variability in ventilatory responses could not be calculated. However, a previous study of hyperoxic responses of infants recorded in quiet sleep, indicated that intra-subject variability, at least to this test, was low (approximately 12\%). ${ }^{21}$

\section{Summary}

The prerequisite for adequate respiration is an ability to promptly sense and respond to changes in arterial carbon dioxide and oxygen levels. A delayed response to $\mathrm{CO}_{2}$ and $\mathrm{O}_{2}$ and somewhat diminished response to $\mathrm{CO}_{2}$ suggests that an inappropriate central control of respiration is an important mechanism in the pathogenesis of apnoea of infancy.

\section{ACKNOWLEDGEMENTS}

The author wishes to thank Siv Öhman-Spetz and Yvonne Oddbratt for their skilful polysomnographic recordings, Maria Wennborg for excellent administrative assistance, and Dr Gary Cohen for the English revision and the stimulating scientific discussions.

This study was supported by grants from Karolinska Institute Funds and Sällskapet Barnavård.

\section{REFERENCES}

1 Garay SM, Rapoport D, Sorkin B, et al. Regulation of ventilation in the obstructive sleep apnoea syndrome. Am Rev Respir Dis 1981;124:451-7.

2 Osanai S, Akiba Y, Fujiuchi S, et al. Depression of peripheral chemosensitivity by a dopaminergic mechanism in patients with obstructive sleep apnoea syndrome. Eur Respir J 1999;13:418-23.

3 Sin DD, Jones RL, Man GC. Hypercapnic ventilatory response in patients with and without obstructive sleep apnea: do age, gender, obesity, and daytime $\mathrm{PaCO}_{2}$ matter? Chest 2000;117:454-9.

4 Benlloch E, Cordero P, Morales $\mathrm{P}$, et al. Ventilatory pattern at rest and response to hypercapnic stimulation in patients with obstructive sleep apnea syndrome. Respiration 1995;62:4-9.

5 Appelberg J, Sundström G. Ventilatory response to $\mathrm{CO} 2$ in patients with snoring, obstructive hypopnoea and obstructive apnoea. Clin Physiol 1997; 17:497-507

6 Narkiewicz K, van de Borne PJH, Pesek CA, et al. Selective potentiation of peripheral chemoreflex sensitivity in obstructive sleep apnea. Circulation 1999;99:1183-9.

7 Rigatto H, Brady JP. Periodic breathing and apnoea in preterm infants. I. Evidence for hypoventilation possibly due to central nervous depression. Pediatrics 1972;50:202-18.

8 Barrington K, Finer N. The natural history of the appearance of apnea of prematurity. Pediatr Res 1991;29:372-5.

9 Alvaro RE, Weintraub Z, Kwiatkowski K, et al. Speed and profile of the arterial peripheral chemoreceptors as measured by ventilatory changes in preterm infants. Pediatr Res 1992;32:226-9.

10 Hazinski TA, Severinghaus JW, Marin MS, et al. Estimation of ventilatory response to carbon dioxide in newborn infants using skin surface gas electrodes. Pediatrics 1984; 105:389-93.

11 Gozal D, Arens R, Omlin KJ, et al. Ventilatory response to consecutive short hypercapnic challenges in children with obstructive sleep apnea. J Appl Physiol 1995;79:1608-14.

12 Marcus CL, Lutz J, Caroll JL, et al. Arousal and ventilatory responses during sleep in children with obstructive sleep apnea. J Appl Physiol 1998;84: 1926-36.

13 Upton CJ, Milner AD, Stokes GM. Upper airway patency during apnoea of prematurity. Arch Dis Child 1992;67:419-24.

14 Idiong N, Lemke RP, Lin YJ, et al. Airway closure during mixed apneas in preterm infants: is respiratory effort necessary? J Pediatr 1998;133:509-12.

15 Lemke RP, Idiong N, Al-Saedi S, et al. Evidence of a critical period of airway instability during central apneas in preterm infants. Am J Respir Crit Care Med 1998;157:470-4.

16 Badr MS, Toiber F, Skatrud JB, et al. Pharyngeal narrowing/occlusion during central sleep apnea. J Appl Physiol 1998;78:1806-15.

17 Worsnop C, Kay A, Kim Y, et al. Effect of age on sleep onset-related changes in respiratory pump and airway muscle function. $J$ Appl Physiol 2000:88:1831-9.

18 Katz-Salamon $M$, Jonsson B, Lagercrantz $H$. Blunted peripheral chemoreceptor response to hyperoxia in a group of infants with BPD. Pediatr Pulmonol 1995;20:101-7.

19 Katz-Salamon M, Lagercrantz H. Hypoxic ventilatory defense in very preterm graduates - attenuation after long oxygen treatment. Arch Dis Child 1994;70:90-5.

20 Bouferrache B, Filtchev S, Leke A, et al. The hyperoxic test in infants reinvestigated. Am J Respir Care Med 2000;161:160-5.

21 Katz-Salamon M. Milerad J. The divergent ventilatory and heart rate cardiac responses to moderate hypercapnia in infants with apparent life threatening events (ALTE) and recurrent apnoeas of other causes. Arch Dis Child 1998;79:231-6.

22 Kelly DH, Walker AM, Cahen L, et al. Periodic breathing in siblings of sudden infant death syndrome victims. Pediatrics 1979;66:515-20.

23 Prechtl HFR. The behavioural states of the newborn infants (a review). Brain Res 1974;76:185-212.

24 Weintraub Z, Cates D, Kwiatkowski K, et al. The morphology of periodic breathing in infants and adults. Respir Physiol 2001;127:173-84.

25 Barrington KJ, Finer NN, Wilkinson MH. Progressive shortening of the periodic breathing cycle duration in normal infants. Pediatr Res 1987;21:247-51.

26 Weiner D, Mitra J, Salamone J, et al. Effect of chemical stimuli on nerves supplying upper airway muscles. J Appl Physiol 1982;52:530-6.

27 Singer LP, Saenger P. Complications of pediatric OSA. Otolaryngol Clin North Am 1990;24:665-75.

28 Cross KW, Klaus M, Tooley WH, et al. The response of the newborn baby to inflation of the lungs. J Physiol 1960;151:551-65.

29 Bodegård G, Schweiler GH, Skoglund S, et al. Control of respiration in newborn babies. Acta Paediatr 1969;58:567-71.

30 Olinsky A, Bryan MH, Bryan AC. Influence of lung inflation on respiratory control in neonates. J Appl Physiol 1974;36:426-9.

31 Davi M, Sankaran K, MacCallum M, et al. The effect of sleep state on chest distortion and on the ventilatory response to $\mathrm{CO}_{2}$ in neonate. Pediatr Res 1979;13:982-6.

32 Williams BA, Smyth J, Boon AW, et al. Development of respiratory chemoreflexes in response to alternations of fractional inspired oxygen in newborn infant. J Physiol 1991;442:81-90 